\title{
Determination of concentration of saturated ferrocene in aqueous solution
}

\author{
This article was published in the following Dove Press journal: \\ Reports in Electrochemistry \\ 26 July 2013 \\ Number of times this article has been viewed
}

\author{
Chun Ouyang \\ Koichi Jeremiah Aoki \\ Jingyuan Chen \\ Toyohiko Nishiumi \\ Bo Wang \\ Department of Applied Physics, \\ University of Fukui, Bunkyo, \\ Fukui, Japan
}

\begin{abstract}
The solubility of ferrocene in aqueous solution is known to be approximately $0.04 \mathrm{mmol} / \mathrm{dm}^{3}$. The solubility values determined by voltammetry have been overestimated because of adsorption on electrodes. This work deals with discerning diffusion from adsorption by altering not only the voltammetric time scale but also the solvents used. Fast voltammetric responses by differential pulse voltammetry and fast scan voltammetry exhibited adsorption behavior. In contrast, quasi steady-state voltammetry showed the diffusion-control, the current of which seemed to evaluate the saturated concentration accurately. However, the currents in the solution including a small amount of organic solvent were smaller than those in the aqueous solution although the concentrations were identical. Solutions including organic solvents have often been used to obtain calibration curves. Therefore, the concentration evaluated from the calibration curve was estimated to be larger than the true concentration. The current in the organic solvent was explained in terms of the extra solvation energy by supersaturation, which was dissipated to low concentrated domains by diffusion. It was formulated in the form of diffusion coefficients. The true concentration was evaluated to be $0.01 \mathrm{mmol} / \mathrm{dm}^{3}$ by slow scan voltammetry in the solution without calibration curves.
\end{abstract}

Keywords: adsorption, ferrocene, aqueous solution, voltammetry, supersaturation

\section{Introduction}

Concentrations of sparingly soluble redox species have been determined quantitatively by pulse techniques such as differential pulse voltammetry ${ }^{1-3}$ and square wave voltammetry. ${ }^{4,5}$ Less affinity of these species for solvent often makes these species adsorb on an electrode. ${ }^{6}$ Then the pulse voltammetric currents may include not only a diffusion-controlled component but also an adsorption-controlled component, an example of which is ferrocene in aqueous solution. ${ }^{7}$ Adsorption contributes to the currents more than diffusion, with a decrease in the pulse width because the chronoamperometric curve for adsorbed species decays faster than that for diffusing species. Therefore, the concentration determined may be overestimated. Calibration curves themselves may include this type of error. It is desirable to be able to evaluate concentrations without using calibration curves. Adsorptive stripping voltammetry is a possible analytical too ${ }^{8-10}$ if a calibration curve can be obtained and if sparingly soluble species can be adsorbed quantitatively on an electrode. A drawback is the difficulty of obtaining a calibration curve.

Microelectrode techniques provide steady-state voltammograms which can circumvent complications by adsorption. However, a drawback of these techniques is the noisy currents of sparingly soluble species because of low concentrations at a small
Correspondence: Koichi Jeremiah Aoki Department of Applied Physics, University of Fukui, 3-9-I Bunkyo, Fukui, $910-0017$ Japan

Tel +81776278665

Fax +81776278750

Email kaoki@u-fukui.ac.jp 
electrode area. This problem can be solved by extremely slow scan voltammetry, as developed by Levi et al and Levi and Aurbach. ${ }^{11,12}$ This method has been widely used for work on lithium batteries, ${ }^{13-18}$ film-coated electrodes in a thin layer cell, ${ }^{19-25}$ and catalytic reactions by measurements for long time. ${ }^{26-30}$ Addition of sodium alginate to aqueous solution suppresses natural convection ${ }^{31}$ without changing the diffusion coefficients of molecules. ${ }^{32-35}$ This technique may allow us to evaluate low concentrations of redox species accurately.

This work deals with voltammetric determination of concentrations of ferrocene saturated in aqueous solution as an example of sparingly soluble species when the measurement time is varied in differential pulse voltammetry, cyclic voltammetry, and slow scan voltammetry. The contribution of adsorption is distinguished from diffusion waves by voltammetric time variations. A new insight provided by work is finding enhancement of mass transport in mixed solvents that have been used to make calibration curves. The concept of enhancement is discussed theoretically.

\section{Methods and materials}

Ferrocene was purified by sublimation to remove $10 \%$ of its impurity. ${ }^{36}$ Water was deionized and distilled. Next, $0.1 \mathrm{M}$ $\mathrm{KCl}\left(\mathrm{M}=\mathrm{mol} / \mathrm{dm}^{3}\right)$ aqueous solution including ferrocene powder was ultrasonicated for ten minutes, and left to stand for a few hours. The saturated solution was filtered and became transparent. We confirmed no precipitation in the solution. Acetonitrile was of analytical grade. The volume of the solution was about $15 \mathrm{~cm}^{3}$.

Sodium alginate powder (Wako Pure Chemical Industries, Ltd, Osaka, Japan) was used as received and yielded 500-600 mPa s in $12 \mathrm{mg} / \mathrm{cm}^{3}$ solution. This was dissolved in distilled water at $60^{\circ} \mathrm{C}$ to yield a homogeneous solution. Air bubbles coming from the powder were removed by ultrasonication for 30 minutes. When nitrogen gas was bubbled into the viscous sodium alginate solution, ultrasonication was applied to remove the bubbles.

Cyclic voltammetry and differential pulse voltammetry were carried out using a potentiostat (Compactstat ${ }^{\text {TM }}$, Ivium Technologies, Eindhoven, the Netherlands). Platinum disks $1.6 \mathrm{~mm}$ and $0.1 \mathrm{~mm}$ in diameter were used as working voltammetric electrodes. The reference electrode was $\mathrm{Ag} \mid \mathrm{AgCl}$ in saturated $\mathrm{KCl}$. The counter electrode was a platinum wire. Viscosity was determined using a vibration viscometer (SV-10, A\&D, Tokyo, Japan) at room temperature.

\section{Results and discussion Adsorption-controlled and diffusion- controlled voltammograms}

Figure 1 shows cyclic voltammograms of the ferrocenesaturated aqueous solution for scan rates of $v \geq 0.1 \mathrm{~V}$ per second at the Pt electrode, $1.6 \mathrm{~mm}$ in diameter. The anodic and cathodic peak potentials were at $0.238 \pm 0.005 \mathrm{~V}$ and $0.182 \pm 0.009 \mathrm{~V}$, respectively. These values are close to the reported ones. ${ }^{7}$ The difference between the anodic and the cathodic potentials was $56 \mathrm{mV}$. Figure 2 shows variation of the peak current against $v$, where the background current was subtracted as shown in the solid line of Figure 1. The proportionality indicates that the peak current is due to an adsorption-controlled step. The amount of adsorption can generally be estimated from the area enclosed with a voltammetric wave and a base line. The background solid line in Figure 1 unfortunately did not pass through the voltammogram in the domain from $0.3 \mathrm{~V}$ to $0.4 \mathrm{~V}$. A curved background might be useful for the estimation. In order to avoid the ambiguity of drawing a curved background, we used the background (dashed) line connecting points at $0.15 \mathrm{~V}$ and $0.35 \mathrm{~V}$ on the voltammogram. This line may provide a minimum amount of the adsorption. The density of adsorbed ferrocene was determined by the inverse of the charge density per electrode area, which was obtained from the area of the peak divided by the scan rate, as shown in Figure 1. This was $(1.1 \pm 0.2) \times 10^{-11} \mathrm{~mol} / \mathrm{cm}^{2}$. This corresponds to $(3.8 \mathrm{~nm})^{2}$ per adsorbed ferrocene molecule, implying the spaced adsorption that is frequently observed for nonaggregated species.

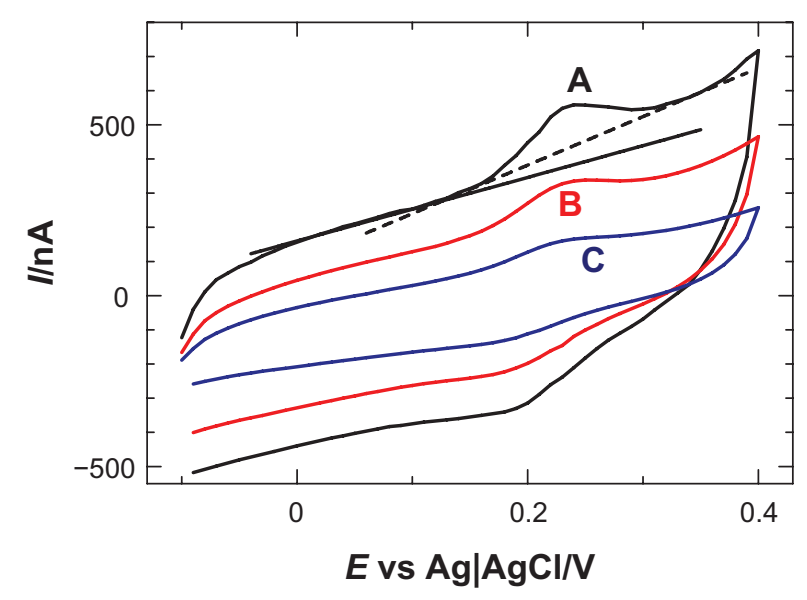

Figure I Cyclic voltammograms of saturated ferrocene in $0.1 \mathrm{M} \mathrm{KCl}$ at a platinum electrode $1.6 \mathrm{~mm}$ in diameter for scan rates, $v=(\mathbf{A}) 0.5$, (B) 0.3 , and (C) $0.1 \mathrm{~V}$ per second. Solid line and dashed line are backgrounds for evaluating oxidation peak current and charge, respectively. 


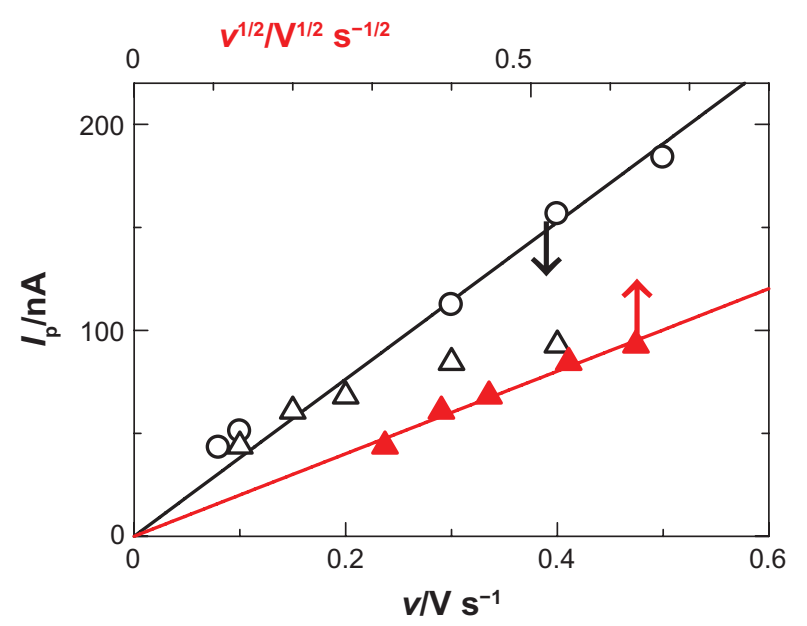

Figure 2 Dependence of background-corrected peak currents of (circles) ferrocene-saturated $0.1 \mathrm{M} \mathrm{KCl}$ aqueous solution and (open triangles) ferrocenesaturated $0.1 \mathrm{M} \mathrm{KCl}$ aqueous solution including $5 \%$ acetonitrile on the scan rates, and ferrocene-saturated $0.1 \mathrm{M} \mathrm{KCl}$ aqueous solution including $5 \%$ acetonitrile on the square roots of the scan rates at the $1.6 \mathrm{~mm}$ disk electrode.

Slow scan voltammograms at a microelectrode are expected to show diffusion ability. Figure 3A and B shows voltammograms for slow scans at an $0.1 \mathrm{~mm}$ Pt electrode. The voltammograms were of sigmoidal form, and did not vary with a scan rate for $v<10 \mathrm{mV}$ per second, as is the ideally diffusion-controlled wave. ${ }^{36}$ Electrodes smaller than a $0.1 \mathrm{~mm}$ disk showed voltammograms with large hysteresis. Reproducible voltammograms for further slower scanning can be realized at a large electrode in sodium alginate solution, which suppresses natural convection without decreasing the diffusion coefficient. ${ }^{35}$ Figure $3 \mathrm{C}$ also shows a linear sweep voltammogram at $v=0.1 \mathrm{mV}$ per second at the $1.6 \mathrm{~mm}$ Pt electrode in ferrocene-saturated solution containing sodium alginate. The Faradaic current level was kept reproducible against the background current for reduction

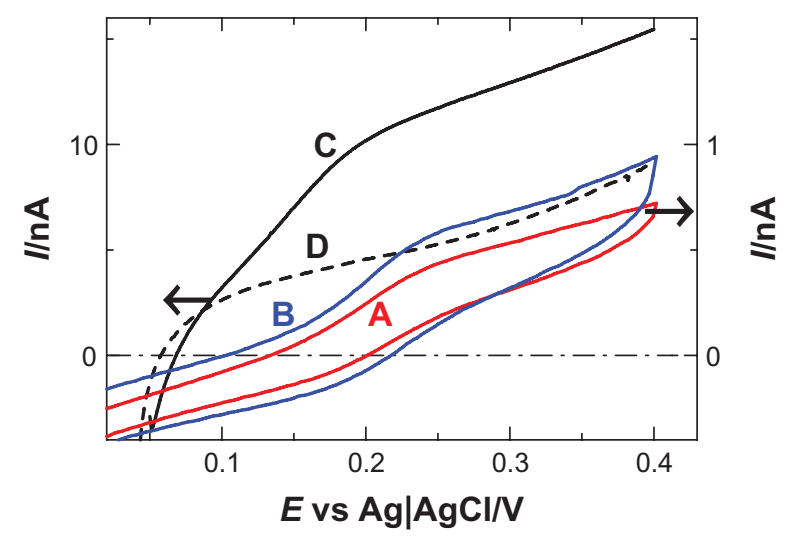

Figure 3 Cyclic voltammogram of saturated ferrocene in $0.1 \mathrm{M} \mathrm{KCl}$ at a platinum electrode $0.1 \mathrm{~mm}$ in diameter for $v=($ A) $5 \mathrm{mV}$ per second and (B) $15 \mathrm{mV}$ per second on the right ordinate and (C) $1.6 \mathrm{~mm}$ in diameter for $v=0.1 \mathrm{mV}$ per second and (D) its background wave on the left ordinate. of oxygen and noise. We confirmed that sodium alginate had no effect on diffusion. ${ }^{35}$

Figure 4 shows dependence of the limiting currents, $I_{\mathrm{L}}$, divided by the electrode radii on $v^{1 / 2}$ at the $0.1 \mathrm{~mm}$ electrode (circles) in ferrocene-saturated aqueous solution and at the $1.6 \mathrm{~mm}$ electrode (triangles) in sodium alginate-included ferrocene-saturated solution. The scan rates of the latter case are much lower than those of the former. The currents have a linear relationship with $v^{1 / 2}$, but do not show proportionality owing to the edge effect. ${ }^{37}$ The slope at the $0.1 \mathrm{~mm}$ electrode was larger than the theoretical diffusion-controlled one, ${ }^{37}$ indicating the effect of adsorption. In contrast, the limiting currents for $0.1 \mathrm{mV}$ per second $\leq v \leq 1 \mathrm{mV}$ per second (triangles in Figure 4) are close to the steady state. From the linearly extrapolated value of $I_{\mathrm{L}} / a$ to $v^{1 / 2} \rightarrow 0$ (triangles) and the steady-state equation, $I_{\mathrm{L}} / a=4 F c D$, we evaluated $c=0.015 \mathrm{mM}$ for $D=0.7 \times 10^{-5} \mathrm{~cm}^{2}$ per second. The concentration is smaller than the reported value (approximately $0.04 \mathrm{mM}$ ). The problem of the present measurement is whether the adsorption effect is still included or not.

The conventional technique of determination is differential pulse voltammetry. We performed pulse voltammetry for ferrocene in both an aqueous solution and a mixed solution. A peak appeared at $0.16 \mathrm{~V}$ in both the ferrocene-saturated solution and in the concentration-controlled mixed solvents, as shown in Figure 5. Peak currents in the mixed solvents were proportional to the concentrations of ferrocene for several values of pulse width. Proportionality was used as the calibration line for determination of concentration in the ferrocene-saturated solution. Figure 6 shows the variation in concentration determined with pulse width. The longer the pulse width, the lower the concentration found.

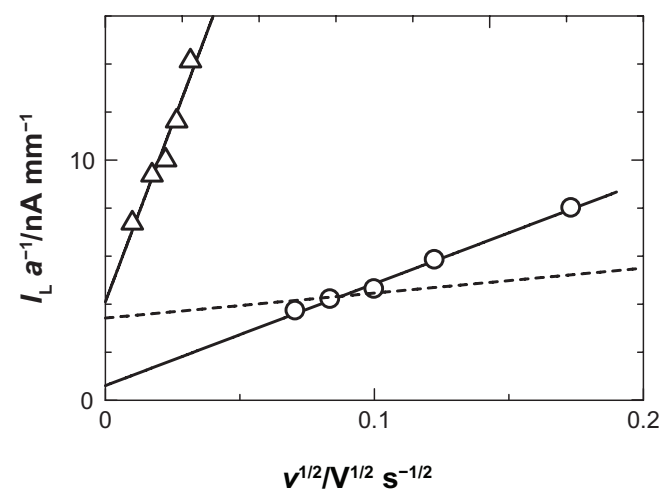

Figure 4 Variations of $I_{p} / a$ with $v^{1 / 2}$ on the lower ordinate and those of $I_{p} / a$ with $p$ on the upper ordinate. Voltammograms were obtained (circles) in the ferrocenesaturated solution at the $0.1 \mathrm{~mm}$ platinum electrode and (triangles) in the ferrocenesaturated solution containing sodium alginate at the $1.6 \mathrm{~mm}$ disk electrode. The dashed line is the diffusion-controlled variation predicted theoretically. ${ }^{36}$ 


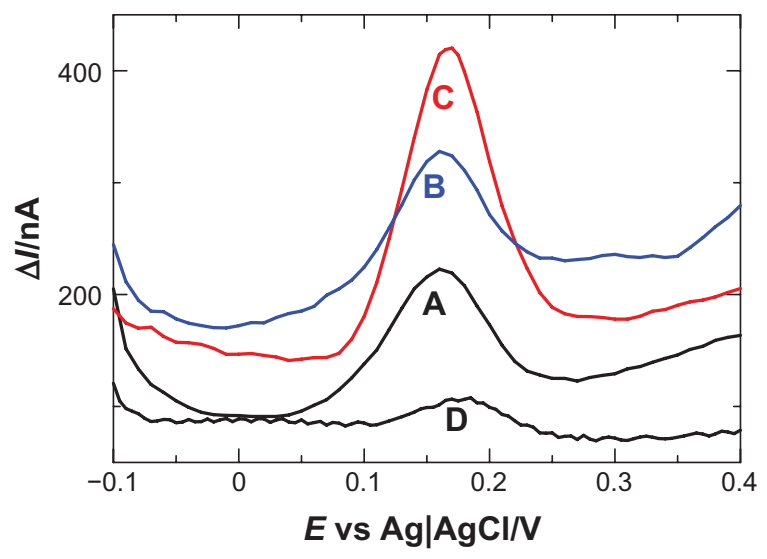

Figure 5 Differential pulse voltammograms of ferrocene $(\mathbf{A})$ deliberately dissolved in $0.1 \mathrm{M} \mathrm{KCl}$ solution, and dissolved in a mixture of acetonitrile and water at $\mathrm{I}: 20(\mathrm{v} / \mathrm{v})$ so that the concentration was (B) $48 \mu \mathrm{M}$ and (C) $97 \mu \mathrm{M}$. Pulse conditions were pulse width $15 \mathrm{msec}$, pulse amplitude $25 \mathrm{mV}$, and scan rate $0.0 \mathrm{I} \mathrm{V}$ per second. (D) was observed under the conditions of $(\mathbf{A})$ except for pulse width, $100 \mathrm{msec}$.

The concentration values approach the quasi-state value (dashed line) obtained above. Given that the electrolysis time for pulse voltammetry is much shorter than that of cyclic voltammetry in Figure 1, the pulse current in the aqueous solution should be controlled by adsorption. On the other hand, the calibration lines made in the mixed solvent were expected to provide diffusion-controlled current. Therefore, inconsistency of conditions between calibration and sampling provides erroneous concentrations. Because the difference is remarkable with a decrease in pulse width, the shorter time response yields higher concentrations in Figure 6.

\section{Voltammograms in mixed solutions}

A strategy for preventing adsorption of ferrocene is to facilitate dissolution either in solution containing a surfac$\operatorname{tant}^{7}$ or water-miscible mixed solvents. ${ }^{8}$ We used the latter

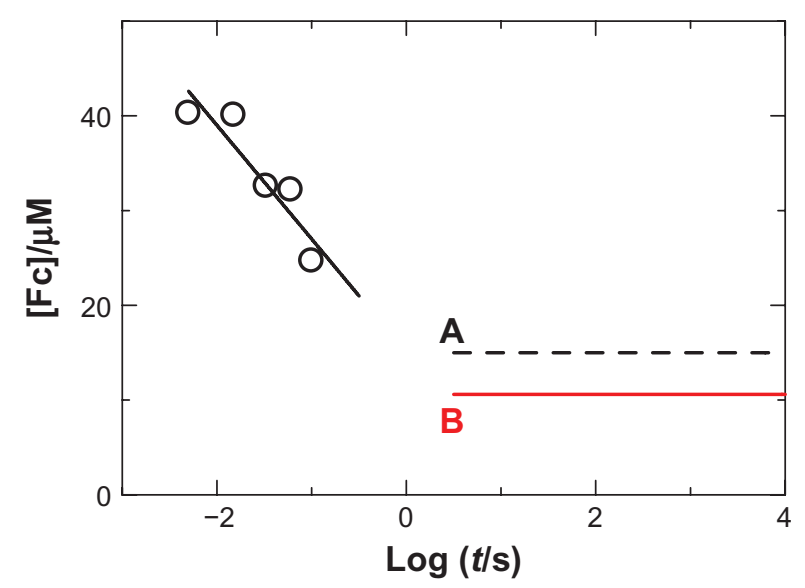

Figure 6 Dependence of concentrations of saturated ferrocene on measurement times by (circles) differential pulse voltammogram, (A) very slow linear sweep voltammetry and (B) linear sweep voltammetry with addition of acetonitrile. here because mass transport in mixed solvents is simpler than diffusion of micelles. We used a mixed solvent of acetonitrile in water. An aqueous solution of saturated ferrocene was prepared first, and a 5\% volume of acetonitrile was then added to this solution. The voltammetric shape in the mixed solution was very similar to that in the aqueous solution. Figure 2 shows the plot of the peak current against $v$ and $v^{1 / 2}$ in the acetonitrile-mixed solution. The peak current was proportional to $v^{1 / 2}$ rather than $v$. This is evidence of removing adsorption owing to dissolution of ferrocene in the mixed solvent.

The current was smaller than that in the aqueous solution, as shown in Figure 2. This variation is opposite to the difference between the viscosity of the solution containing acetonitrile $\left(1.1_{7} \mathrm{mPa} \mathrm{s}\right)$ and that of the aqueous solution $\left(1.3_{2} \mathrm{mPa} \mathrm{s}\right)$ at $21^{\circ} \mathrm{C}$. Supersaturated ferrocene in aqueous solution obviously has higher energy than that in the mixed solvent. When the concentration of ferrocene is decreased by consumption of the electrode reaction near the electrode, the high energy of the supersaturation may be dissipated to the domain with the lower concentration. Mass transport may then be facilitated. The concept and theory behind this is described in the following paragraphs.

We obtained two points for the ambiguity of determination of saturated concentration.

First, the voltammetric current at a short time is controlled by adsorption, whereas that at a long time is by diffusion. Therefore, concentrations evaluated at a short time are larger than those at a long time. Only slow voltammetry can be valid for accurate determination of sparingly soluble species. Second, a sparingly soluble species in supersaturation has a larger diffusion coefficient than that in the dissolved state. Therefore, a saturated species shows currents larger than those predicted from the known value of the diffusion coefficient.

In order to overcome the two points simultaneously, slow scan voltammetry was performed in a ferrocene-saturated solution to which $5 \%$ acetonitrile was added. A calibration curve was not required when we used a combination of cyclic voltammetry with $0.1<v<0.4 \mathrm{~V}$ per second at a regular sized electrode $(1.6 \mathrm{~mm}$ in diameter) and with quasi-steady-state voltammetry at a small electrode $(0.1 \mathrm{~mm}$ in diameter). ${ }^{36}$ Voltammograms at the regular electrode were similar to that in Figure 1, whereas those at the small electrode were of sigmoidal form. Figure 7 shows plots of the peak currents and the limiting currents against $v^{1 / 2}$. The peak currents were proportional to $v^{1 / 2}$, whereas the limiting currents fell on a line with an intercept. By taking the ratio 


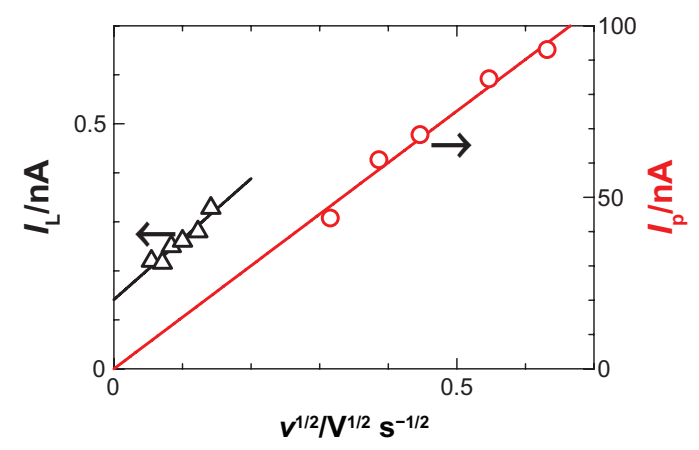

Figure 7 Dependence of $I_{p}$ and $I_{L}$ in saturated ferrocene solution to which acetonitrile was added on $v^{1 / 2} . I_{p}$ and $I_{L}$ were obtained at $1.6 \mathrm{~mm}$ and $0.1 \mathrm{~mm}$ electrodes, respectively.

of the slope of the proportional line and the intercept,${ }^{36}$ we evaluated $D=0.68 \times 10^{-5} \mathrm{~cm}^{2}$ per second and $c=10^{-6} \mu \mathrm{M}$. The value of the diffusion coefficient is reasonable, and hence the concentration is reliable. ${ }^{36}$ The concentration value is plotted in Figure 6B. It is the smallest of the other techniques because the effects of the two sources of ambiguity described above were removed.

\section{Diffusion theory of sparingly soluble species}

This section deals with the theory of enhancement of the diffusion coefficient of supersaturated ferrocene. If extra energy of supersaturation is formulated as a function of concentration, the diffusion coefficient can be expressed in terms of the concentration. The derivation proceeds in the following steps: derivation of the expression for free energy of supersaturation, introduction of the chemical potential of supersaturated species, and derivation of the diffusion equation depending on the concentration.

Our model is composed of $n_{1}$ solute molecules under supersaturation and $n_{2}$ solvent molecules. When $n_{1}$ increases by $\Delta n_{1}$, the enthalpy relevant to the solubility, $H\left(n_{1}\right)$, increases in proportion to $\Delta n_{1}$ as a variable of the amount. Because the solute is forced to be dissolved against ordinary enthalpy, the increment of the enthalpy should be proportional to $H\left(n_{1}\right)$ as an intensity variable. In total, the enthalpic increment is proportional to $H\left(n_{1}\right) \Delta n_{1}$. Then we have

$$
H\left(n_{1}+\Delta n_{1}\right)=H\left(n_{1}\right)+k H\left(n_{1}\right) \Delta n_{1} / N
$$

where $k$ is a dimensionless constant and $N=n_{1}+n_{2}$ is the total number of molecules in the volume $V$. Taking the Taylor expansion on the left hand side and keeping the first and second terms, we have

$$
\mathrm{d} H\left(n_{1}\right) / \mathrm{d} n_{1}=(k / N) H\left(n_{1}\right)
$$

A solution has the form of $\exp \left(k n_{1} / N\right)$. Letting the enthalpy in $V$ at the critical number, $n_{\text {cr }}$, be $H_{\text {cr }}$, the enthalpy is expressed by

$$
H\left(n_{1}\right)=H_{\text {cr }} \exp \left(k\left(n_{1}-n_{\text {cr }}\right) / N\right)
$$

The total free energy of solute and solvent is generally written as the sum of two species, $n_{1} \mu_{1}^{\circ}+n_{2} \mu_{2}^{\circ}$ and the mixing entropic term, $k_{\mathrm{B}} T\left[n_{1} \ln \left(n_{1} / N\right)+n_{2} \ln \left(n_{2} / N\right)\right]$, where $\mu_{1}^{\circ}$ and $\mu_{2}^{\circ}$ are standard chemical potentials of the solute and solvent per molecule. Since the solute is in the supersaturated state, free energy includes the contribution of excess enthalpy. The free energy in $V$ is then given by

$$
\begin{aligned}
G= & n_{1} \mu_{1}^{\circ}+n_{2} \mu_{1}^{\circ}+H_{\mathrm{cr}} \exp \left(k\left(n_{1}-n_{\mathrm{cr}}\right) / N\right) \\
& +k_{\mathrm{B}} T\left(n_{1} \ln \left(n_{1} / N\right)+n_{2} \ln \left(n_{2} / N\right)\right)
\end{aligned}
$$

The chemical potential of the solute, defined by $\mu_{1}=\partial G / \partial n_{1}$ for a constant $n_{2}$, is given by

$$
\mu_{1}=\mu_{1}^{\circ}+(k / N) H_{\text {cr }} \exp \left(k\left(n_{1}-n_{\text {cr }}\right) / N\right)+k_{\mathrm{B}} T \ln \left(n_{1} / N\right)
$$

When $n_{1}$ in Equation (5) can be represented by the volume concentrations, $c=n_{1} / N V$ and $c_{\mathrm{cr}}=n_{\mathrm{cr}} / N V$, Equation (5) becomes

$$
\mu_{1}=\mu_{1}^{\circ}+(k / N) H_{\text {cr }} \exp \left(k V\left(c-c_{\text {cr }}\right)\right)+k_{\mathrm{B}} T \ln \left(c / c^{\circ}\right)
$$

where $c^{\circ}$ is the standard concentration.

When the solute has heterogeneity in concentration, the gradient in the $x$ direction is given by

$$
\frac{\mathrm{d} \mu_{1}}{\mathrm{~d} x}=\left(\left(k^{2} H_{\text {cr }} V / N\right) \exp \left(k V\left(c-c_{\text {cr }}\right)\right)+\frac{k_{\mathrm{B}} T}{c}\right) \frac{\mathrm{d} c}{\mathrm{~d} x}
$$

The solute molecule is driven by the force, $\mathrm{d} \mu_{1} / \mathrm{d} x$, to reach the steady-state velocity, $u$, being balanced with Stokes' friction for a spherical molecule, $6 \pi \eta r u$, where $\eta$ is the viscosity of the solvent. Rewriting Equation (7) by use of the flux, $J=c u$, we have

$$
J=-D\left(1+\frac{k^{2} H_{\mathrm{cr}} V c}{N k_{\mathrm{B}} T} \exp \left(k V\left(c-c_{\mathrm{cr}}\right)\right)\right) \frac{\mathrm{d} c}{\mathrm{~d} x}
$$

where $D=k_{\mathrm{B}} T / 6 \pi \eta r$. When $N$ is taken to be Avogadro's constant, $V$ means the average molar volume of the solution. Then Equation (8) becomes 


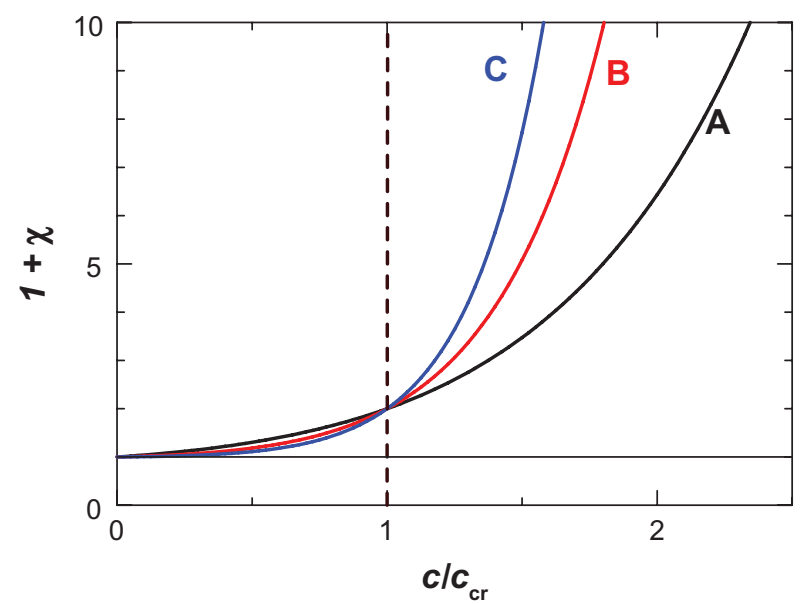

Figure 8 Variation of dimensionless diffusion coefficient with concentration for $k V_{\mathrm{M}} / c_{\mathrm{cr}}=(\mathbf{A}) \mathrm{I}$, (B) 2, and (C) 3 at $k^{2} V_{\mathrm{M}} H_{\mathrm{cr}} / R T c_{\mathrm{cr}}=\mathrm{I}$, calculated from equation (9).

$$
\begin{aligned}
& J=-D(1+\chi)(\mathrm{d} c / \mathrm{d} x) \\
& \chi=\frac{k^{2} V_{\mathrm{M}} H_{\mathrm{cr}} c}{R T} \exp \left(k V_{\mathrm{M}}\left(c-c_{\mathrm{cr}}\right)\right)
\end{aligned}
$$

Variations of the dimensionless diffusion coefficient, $1+\chi$, are shown in Figure 8 for parameters $k V_{\mathrm{M}} / c_{\mathrm{cr}}$ and $k^{2} V_{\mathrm{M}} H_{\mathrm{cr}} /$ $R T c_{\text {cr. }}$. When $c$ increases from the critical concentration, the diffusion coefficient enhances tremendously. This is the theoretical demonstration of enhancement of diffusion-controlled currents near saturation.

\section{Conclusion}

Voltammetric determination of ferrocene saturated in aqueous solution is complicated by adsorption of ferrocene at an electrode, and hence the observed voltammetric current is larger than that predicted from the diffusion equation. Known concentrations for making calibration curves have to be prepared using mixed solvents, in which ferrocene is not adsorbed on the electrode. Therefore, use of calibration curves is not suitable for determination of sparingly soluble species. The shorter the voltammetric time scale, the more remarkable the adsorption effects. Steady-state measurements are desirable.

The other important point for determination is enhancement of mass transport of saturated ferrocene. This can be explained in terms of the extra energy of the dissolution, which is dissipated to the lower concentration domain near the electrode. This dissipation is equivalent to the enhancement of diffusion. The degree of enhancement can be estimated from the present simple theory. This effect can be solved by addition of a small amount of acetonitrile to the saturated solution. The current in the solution containing acetonitrile is approximately half that in the saturated aqueous solution. The concentration of saturated ferrocene is $10 \mu \mathrm{M}$.

\section{Acknowledgment}

This work was supported financially by Grants-in-Aid for Scientific Research (25420920) from the Ministry of Education in Japan.

\section{Disclosure}

The authors report no conflicts of interest in this work.

\section{References}

1. Berbel F, Diaz-Cruz JM, Ariño C, Esteban M. Voltammetry of sparingly soluble metal complexes: a differential pulse polarographic study of the Zn(II)+oxalate system. J Electroanal Chem. 1999;475:99-106.

2. Carrazon JMP, Garcia AJR, Diez LMP. Voltammetric determination of indole in micellar and emulsified media. J Electroanal Chem. 1987;234:175-183.

3. Shul G, Opallo M, Marken F. Electrochim Acta. 2005;50:2315.

4. Mirčeski V, Skrzypek S, Lovrić, M. Cathodic stripping voltammetry of uracil. Experimental and theoretical study under conditions of square wave voltammetry. Electroanalysis. 2009;21(1):87-95.

5. Oliveira Brett AM, Matysik FM. Voltammetric and sonovoltammetric studies on the oxidation of thymine and cytosine at a glassy carbon electrode. J Electroanal Chem. 1997;429:95-99.

6. Ohsawa Y, Aoyagui S. A correlation between the half-wave potential and the micelle-solubilization equilibrium of ferrocene in cationic micellar solutions. J Electroanal Chem. 1982;136:353-360.

7. Bond AM, McLennan EA, Stojanovic RS, Thomas FG. Assessment of conditions under which the oxidation of ferrocene can be used as a standard voltammetric reference process in aqueous media. Anal Chem. 1987;59:2853-2860.

8. van den Berg CMG. Potentials and potentialities of cathodic stripping voltammetry of trace elements in natural waters. Anal Chim Acta. 1991;250:265-276.

9. Kalvoda R. In: Zyka J, editor. Instrumentation in Analytical Chemistry. New York, NY: Ellis Horwood; 1994.

10. Wang J. Adsorptive Stripping Voltammetry. Am Lab. 1985;17:41-45.

11. Levi MD, Aurbach D. The mechanism of lithium intercalation in graphite film electrodes in aprotic media. Part 1. High resolution slow scan rate cyclic voltammetric studies and modeling. J Electroanal Chem. 1997;421:79-88.

12. Levi MD, Levi EA, Aurbach D. The mechanism of lithium intercalation in graphite film electrodes in aprotic media. Part 2. Potentiostatic intermittent titration and in situ XRD studies of the solid-state ionic diffusion. J Electroanal Chem. 1997;421:89-97.

13. Minakshi M. Lithium intercalation into amorphous $\mathrm{FePO}_{4}$ cathode in aqueous solutions. Electrochim Acta. 2010;55:9174-9178.

14. Ohzuku T, Iwakoshi Y, Sawai K. Formation of Lithium-Graphite Intercalation Compounds in Nonaqueous Electrolytes and Their Application as a Negative Electrode for a Lithium Ion (Shuttlecock) Cell. J Electrochem Soc. 1993;140:2490-2498.

15. Nobili F, Dsoke S, Mancini M, Tossici R, Marassi R. Electrochemical investigation of polarization phenomena and intercalation kinetics of oxidized graphite electrodes coated with evaporated metal layers. J Power Sources. 2008;180:845-851.

16. Lu Z, Levi MD, Salitra G, GoferY, Levi E, Aurbach D. Basic electroanalytical characterization of lithium insertion into thin, well-crystallized $\mathrm{V}_{2} \mathrm{O}_{5}$ films. J Electroanal Chem. 2000;491:211-221.

17. Liberatore M, Decker F, Vuk AS, Orel B, Drazic G. Effect of the organic-inorganic template ICS-PPG on sol-gel deposited $\mathrm{V}_{2} \mathrm{O}_{5}$ electrochromic thin film. Solar Energy Mat. 2006;90:434-443. 
18. Begam KM, Taufiq-Yap YH, Michael MS, Prabaharan SRS. A new NASICON-type polyanion, $\mathrm{Li}_{\mathrm{x}} \mathrm{Ni}_{2}\left(\mathrm{MoO}_{4}\right)_{3}$ as $3-\mathrm{V}$ class positive electrode material for rechargeable lithium batteries. Solid State Ionics. 2004; 172:47-52.

19. Shi C, Anson FC. A simple method for examining the electrochemistry of metalloporphyrins and other hydrophobic reactants in thin layers of organic solvents interposed between graphite electrodes and aqueous solutions. Anal Chem. 1998;70:3114-3118.

20. Shi C, Anson FC. Electron Transfer between Reactants Located on Opposite Sides of Liquid/Liquid Interfaces. J Phys Chem B. 1999;103:6283-6289.

21. Liberatore M, Petrocco A, Caprioli F, La Mesa C, Decker F, Bignozzi CA. Mass transport and charge transfer rates for $\mathrm{Co}^{(\mathrm{III}) /}$ $\mathrm{Co}^{\text {(II) }}$ redox couple in a thin-layer cell. Electrochim Acta. 2010;55: 4025-4029.

22. Chung TD, Effects of electrolytes in a liquid thin layer system, J. Kor. Electrochem Soc. 2002;5:216-220.

23. Quentel F, Mirceski V, L'Her M, Spasovski F, Gacina M. Electrochemical study of hydrophilic ion transfers across cholesterol modified waternitrobenzene interface by means of thin film electrodes. Electrochem commun. 2007;9:2489-2495.

24. Mirceski V, Gulaboski R, Bogeski I, Hoth M. Redox chemistry of Catransporter 2-palmitoylhydroquinone in an artificial thin organic film membrane. J Phys Chem C. 2007;111:6068-6076.

25. Liu X, Hu L, Zhang L, Liu H, Lu X. Electron transfer between reactants ferric ion and decamethyferrocene located on $\mathrm{NB} / \mathrm{H}_{2} \mathrm{O}$ interfaces by thin layer method. Electrochim Acta. 2005;51:467-473.

26. Maillard F, Martin M, Gloaguen F, Leger J-M. Oxygen electroreduction on carbon-supported platinum catalysts. Particle-size effect on the tolerance to methanol competition. Electrochim Acta. 2002;47:3431-3440.

27. Liu Y, Mitsushima S, Ota K, Kamiya N. Electro-oxidation of dimethyl ether on $\mathrm{Pt} / \mathrm{C}$ and $\mathrm{PtMe} / \mathrm{C}$ catalysts in sulfuric acid. Electrochim Acta. 2006;51:6503-6509.
28. Seland F, Tunold R, Harrington DA. Activating and deactivating mass transport effects in methanol and formic acid oxidation on platinum electrodes. Electrochim Acta. 2010;55:3384-3391.

29. Yagi M, Nagai K, Onikubo T, Kaneko M. Charge transfer and molecular distribution of $\mathrm{Ru}(\mathrm{bpy})^{2+} 3$ complex dispersed in a Nafion ${ }^{\circledR}$ membrane as studied by in-situ spectrocyclic voltammetry. J Electroanal Chem. 1995;383:61-66

30. Modestov AD, Tarasevich MR, Pu H. Investigation of methanol electrooxidation on $\mathrm{Pt}$ and $\mathrm{Pt}-\mathrm{Ru}$ in $\mathrm{H}_{3} \mathrm{PO}_{4}$ using MEA with $\mathrm{PBI}-\mathrm{H}_{3} \mathrm{PO}_{4}$ membrane. Journal of Power Sources. 2012;205:207-214.

31. Wang B, Aoki KJ, Chen J, Nishgiumi T. Slow scan voltammetry for diffusion-controlled currents in sodium alginate solutions. J Electroanal Chem. 2013;700:60-64.

32. Grassi M, Colombo I, Lapasin R. Experimental determination of the theophylline diffusion coefficient in swollen sodium-alginate membranes. J Control Release. 2001;76:93-105.

33. Lubas W, Ander P. Sodium ion diffusion coefficients in aqueous salt-free polyelectrolyte solutions. Macromolecules. 1980;13: 318-321.

34. Li Y, Zhao X, Xu Q, Zhang Q, Chen D. Facile preparation and enhanced capacitance of the polyaniline/sodium alginate nanofiber network for supercapacitors. Langmuir. 2011;27:6458-6463.

35. Aoki K, Wang B, Chen J, Nishiumi T. Diffusion coefficients in viscous sodium alginate solutions. Electrochim Acta. 2012;83:348-353. Aoki K, Wang B, Chen J, Nishiumi T. Electrochim Acta. 2012;83:348.

36. Zhang H, Aoki K, Chen J, Nishiumi T, Toda H, Torita E. Voltammetric determination of both concentration and diffusion coefficient by combinational use of regular and microelectrodes. Electroanalysis. 2011;23:947-952.

37. Aoki K, Akimoto K, Tokuda K, Matsuda H, Osteryoung J. Linear sweep voltammetry at very small stationary disk electrodes. J Electroanal Chem. 1984;171:219-230.
Reports in Electrochemistry

\section{Publish your work in this journal}

Reports in Electrochemistry is an international, peer-reviewed, open access journal publishing original research, reports, reviews and commentaries on all areas of electrochemistry. The manuscript management system is completely online and includes a very quick and fair

\section{Dovepress}

peer-review system. Visit http://www.dovepress.com/testimonials.php to read real quotes from published authors. 